\title{
Metal-Organic Framework-Based Sustainable Nanocatalysts for CO Oxidation
}

\author{
Luis A. Lozano, Betina M. C. Faroldi, María A. Ulla and Juan M. Zamaro *(D) \\ Instituto de Investigaciones en Catálisis y Petroquímica, INCAPE (FIQ, UNL, CONICET), \\ Santiago del Estero 2829 (3000), Santa Fe, Argentina; llozano@fiq.unl.edu.ar (L.A.L.); \\ bfaroldi@gmail.com (B.M.C.F.); mulla@fiq.unl.edu.ar (M.A.U.) \\ * Correspondence: zamaro@fiq.unl.edu.ar
}

Received: 17 December 2019; Accepted: 14 January 2020; Published: 17 January 2020 updates

\begin{abstract}
The development of new catalytic nanomaterials following sustainability criteria both in their composition and in their synthesis process is a topic of great current interest. The purpose of this work was to investigate the preparation of nanocatalysts derived from the zirconium metal-organic framework UiO-66 obtained under friendly conditions and supporting dispersed species of non-noble transition elements such as $\mathrm{Cu}, \mathrm{Co}$, and $\mathrm{Fe}$, incorporated through a simple incipient wetness impregnation technique. The physicochemical properties of the synthesized solids were studied through several characterization techniques and then they were investigated in reactions of relevance for environmental pollution control, such as the oxidation of carbon monoxide in air and in hydrogen-rich streams (COProx). By controlling the atmospheres and pretreatment temperatures, it was possible to obtain active catalysts for the reactions under study, consisting of Cu-based UiO-66-, bimetallic $\mathrm{CuCo}-\mathrm{UiO}-66-$, and $\mathrm{CuFe}-\mathrm{UiO}-6$-derived materials. These solids represent new alternatives of nanostructured catalysts based on highly dispersed non-noble active metals.
\end{abstract}

Keywords: UiO-66; copper; iron; cobalt; nanocatalyst; CO oxidation; COProx

\section{Introduction}

The use of metal-organic frameworks (MOFs) as host matrices to disperse metal nanoparticles is a topic of great interest in the ongoing research for new nanocatalysts. MOFs have the advantage of presenting a variety of transition metals and a wide range of organic ligands in their composition, which makes them attractive for applications in catalysis [1,2]. There are several alternatives to obtain catalytic functionality in the structure of MOFs. One is based on the coordination around metal centers or structural defects that are not committed to the material framework, which can act as active sites [3]. Another possibility is to take advantage of the ligand chemistry since terephthalates or tricarboxylates to which acidic or basic functional groups can be added are usually used [4]. Moreover, the large internal volume available in these materials can be used to host active species [5]. In addition, in recent years, the use of MOFs as templates, which according to their construction units can generate nanostructured metal/metal oxide systems [6], became a consolidated strategy. For example, Sun et al. [7] reported a number of catalysts obtained with this concept, such as $\mathrm{Co}_{3} \mathrm{O}_{4}$ materials from Co-based MOFs or $\alpha-\mathrm{Fe}_{2} \mathrm{O}_{3}$ and $\mathrm{Fe}_{3} \mathrm{O}_{4}$ nanomaterials from Fe-MIL-88B. $\mathrm{CuO}$ and $\mathrm{CuO}-\mathrm{CeO}_{2}$ nanoparticle-based catalysts derived from the MOF HKUST-1 with high catalytic activity were also reported [8].

On the other hand, the catalytic oxidation of carbon monoxide in gaseous streams is a reaction of great environmental relevance. Carbon monoxide is one of the main pollutants of indoor and industrial environments because, due to its high affinity for hemoglobin, it is extremely toxic to living beings [9] and, therefore, numerous studies are currently being conducted for their catalytic removal [10]. Moreover, the elimination of this gas in concentrated hydrogen streams (COProx) has 
significance in the field of renewable energy, as it is one of the most accepted alternatives to carry out the final purification of $\mathrm{H}_{2}$ to be used in fuel cells [11]. For the $\mathrm{CO}$ oxidation, numerous catalytic formulations were tested to date, and those composed of supported oxides represent one of the most promising alternatives [12]. For example, catalysts based on supported particles of copper oxides, cobalt oxides, and iron oxides showed good performance [13-15]. These types of solids avoid the use of noble metals traditionally used in this reaction such as $\mathrm{Pt}, \mathrm{Pd}$, or $\mathrm{Au}$ [12], some of which were also supported in MOFs [16,17]. These elements have a limited abundance and involve much higher costs; thus, efforts are being made for the development of catalysts based on non-noble metals. Currently, it is considered that the use of precious metals is not sustainable compared to earth-abundant metals which are available in orders-of-magnitude higher quantities [18]. Of special interest are the metals of the first transition period, such as $\mathrm{Cu}, \mathrm{Co}$, and $\mathrm{Fe}$, since they are not only less expensive but also less toxic compared to those of the second and third period [19]. Since MOFs have high specific surface areas, they represent a new support alternative for the efficient and low-cost obtainment of catalysts based on dispersed non-noble metal species. In this scenario, UiO-66 is an attractive structure for this purpose since it is a microporous zirconium terephthalate forming a three-dimensional arrangement with high specific surface area and good thermal, mechanical, and chemical stability [20]. In addition, it requires low-cost precursors for its synthesis and can be obtained under fairly sustainable conditions. Very recently, active catalysts based on atomically dispersed ionic $\mathrm{Cu}$ species on UiO-66 and hybrid nanostructures of $\mathrm{CuO}$ nanocrystals encapsulated in $\mathrm{UiO}-66$ crystals were reported [21,22]. In addition, with the concept of a matrix, $\mathrm{CuO} / \mathrm{CeO}_{2}$ active catalysts derived from $\mathrm{Ce}-\mathrm{UiO}-66$ were obtained, as well as $\mathrm{CuCe} / \mathrm{ZrO}_{2}$ catalysts derived from metal-impregnated UiO-66 [23,24].

In this context, the present work proposes to systematically analyze the use of UiO-66 synthesized through a sustainable protocol [25] as a dispersion matrix of $\mathrm{Cu}, \mathrm{Co}$, and Fe species to obtain new nanoparticle structures with potential use in catalysis. In addition, the incorporation of these metallic species is proposed by simple procedures traditionally used to prepare supported catalysts, such as the incipient wetness impregnation with precursors and subsequent thermal decomposition. The physicochemical properties of the obtained nanomaterials were tested in the gas-phase oxidation of carbon monoxide in air streams and in the CO preferential oxidation in hydrogen-rich streams (COProx).

\section{Materials and Methods}

\subsection{Synthesis of UiO-66}

Benzenedicarboxylic acid (BDC, Aldrich, 98.0\% purity, St. Louis, MO, USA), $\mathrm{ZrCl}_{4}$ (Zr, Aldrich, 98.0\% purity, Darmstadt, Germany), and acetone (Cicarelli, 99.0\% purity, San Lorenzo, Argentina) were used without further purification, and UiO-66 synthesis was performed employing a sustainable protocol reported elsewhere [25]. Briefly, the procedure consisted of mixing the two solid reactants together with the solvent in the molar proportions BDC: $\mathrm{ZrCl}_{4}$ :solvent $=1: 1: 1622$. After obtaining the homogeneous mixture, it was placed under solvothermal treatment at $80^{\circ} \mathrm{C}$ for $24 \mathrm{~h}$. At the end of the treatments, the solids were recovered by centrifugation $(10,000 \mathrm{rpm}, 10 \mathrm{~min})$, washed twice with ethanol, and finally dried at $80^{\circ} \mathrm{C}$ overnight.

\subsection{Incorporation of Metallic Species}

$\mathrm{Cu}\left(\mathrm{NO}_{3}\right)_{2} \cdot 3 \mathrm{H}_{2} \mathrm{O}$ (Aldrich, 98.0-103\% purity, St. Louis, MO, USA), $\mathrm{Co}\left(\mathrm{NO}_{3}\right)_{2} \cdot 6 \mathrm{H}_{2} \mathrm{O}$ (Alfa Aesar, $98.5 \%$ purity, Tewksbury, MA, USA), and $\mathrm{Fe}\left(\mathrm{NO}_{3}\right)_{3} \cdot 9 \mathrm{H}_{2} \mathrm{O}$ (Aldrich, $\geq 99.99 \%$, purity, St. Louis, $\mathrm{MO}$, USA) were employed as metal precursors. For their incorporation to MOF, incipient wetness impregnation was used as described in S1 (Supplementary Materials). The nomenclature employed was the following: First the incorporated metal, then its load in wt.\% with respect to the catalyst total mass, and finally the support which was $\mathrm{MOF}(\mathrm{M})$ or its degradation product $(\mathrm{Zr})$, i.e., $\mathrm{Cu}_{10} / \mathrm{M}$ or $\mathrm{Cu}_{16} \mathrm{Fe}_{7} / \mathrm{Zr}$. 


\subsection{Catalyst Characterization}

The crystalline structure of the materials was analyzed trough X-ray diffraction (XRD) with a Shimadzu XD-D1 instrument (Shimadzu Corp., Kyoto, Japan, CuK $\alpha$ radiation, $\lambda=1.5418 \AA, 2^{\circ} \mathrm{C} \cdot \mathrm{min}^{-1}$, $30 \mathrm{mV}, 40 \mathrm{~mA}, 2 \theta=5^{\circ}$ to $65^{\circ}$ ). In order to analyze the thermal evolution of the MOF and precursor, thermogravimetric analysis (TGA) and single differential thermal analysis (SDTA) were conducted with a Mettler Toledo STARe (version 4.1, Bristol, UK) TGA/SDTA 851e module from 25 to $800{ }^{\circ} \mathrm{C}$ at $10^{\circ} \mathrm{C} \cdot \mathrm{min}^{-1}$ in air or nitrogen flow $\left(50 \mathrm{~mL} \cdot \mathrm{min}^{-1}\right.$, standard temperature and pressure (STP)). Laser Raman spectroscopy (LRS) was performed using a LabRam spectrometer (Horiba-Jobin-Yvon, Stanmore, UK) coupled to an Olympus confocal microscope (Olympus Corp., Shinjuku, Tokyo, Japan) equipped with a charge-coupled device (CCD) detector cooled to about $200 \mathrm{~K}$. The excitation wavelength was $532 \mathrm{~nm}$ (Spectra Physics argon-ion laser), and the laser power was set at $30 \mathrm{~mW}$. Transmission electron microscopy (TEM) images of the synthesized UiO-66 crystals and metal-based nanocatalysts were acquired using a JEOL 2100 Plus microscope (JEOL Ltd., Tokyo, Japan) equipped with an energy dispersive X-ray (EDX) detector (JEOL Ltd.) and a scanning transmission electron microscope (STEM) (JEOL Ltd.). The samples were milled and suspended in ethanol by ultrasonic treatment, and a drop of the fine suspension was placed on a carbon-coated nickel grid to be loaded into the microscope.

\subsection{Catalytic Evaluations}

The samples were evaluated in a glass tubular reactor connected to a continuous flow system equipped with mass flow controllers (Brooks 4800, Brooks Instrument, Hatfield, PA, USA) and heated with a furnace controlled with a proportional-integral-derivative (PID) system. Before each evaluation, the reactor was heated at different temperatures $\left(200-650^{\circ} \mathrm{C}\right)$ in He or Air flow $\left(30 \mathrm{~mL} \cdot \mathrm{min}^{-1}\right)$ according to the pretreatment required by the sample before its test and maintaining such a temperature for 60 or $120 \mathrm{~min}$. Then, the catalytic tests were performed with a mixture of molar composition $1 \% \mathrm{CO}, 2 \% \mathrm{O}_{2}$ (employing synthetic air) in He balance, maintaining a total flow of $30 \mathrm{~mL} \cdot \mathrm{min}^{-1}$ with an initial mass of the solid of $70 \mathrm{mg}$. Some tests were also performed by adding $50 \%$ of $\mathrm{H}_{2}$ in the reaction stream (COProx), at the same total flow. The catalytic measurements were taken after stabilizing the reactor at different temperatures for $8 \mathrm{~min}$. The CO conversions were determined with an on-line Shimadzu GC-2014 chromatograph (Shimadzu Corp., Kyoto, Japan) equipped with a thermal conductivity detector (TCD) and a 5- $\AA$ molecular sieve packed bed column. CO conversions (XCO were calculated as follows:

$$
\mathrm{XCO}(\%)=\left([\mathrm{CO}]^{0}-[\mathrm{CO}]\right) /[\mathrm{CO}]^{0} \times 100,
$$

where $[\mathrm{CO}]^{0}$ and [CO] are inlet and outlet gas concentrations (ppm), respectively. Moreover, for COProx, the selectivity of $\mathrm{O}_{2}$ to $\mathrm{CO}_{2}$ (S) was calculated as follows [12]:

$$
\mathrm{S}(\%)=\mathrm{XCO}(\%) /\left(\lambda \times\left(\left(\left[\mathrm{O}_{2}\right]^{0}-\left[\mathrm{O}_{2}\right]\right) /\left[\mathrm{O}_{2}\right]^{0}\right)\right),
$$

where $\left[\mathrm{O}_{2}\right]^{0}$ and $\left[\mathrm{O}_{2}\right]$ are inlet and outlet oxygen concentrations (ppm), respectively. In our case, the value of the factor $\lambda$ (excess oxygen in the reaction) was four.

\section{Results and Discussion}

\subsection{Dispersion of Copper Species in UiO-66}

\subsubsection{Study of the Precursor Decomposition}

The obtained MOF corresponded to a crystalline and pure phase of UiO-66 since all its diffraction signals were observed (Figure S1, Supplementary Materials); the most important ones were identified at $2 \theta=7.38^{\circ}, 8.52^{\circ}$, and $25.75^{\circ}$, corresponding to the (111), (200), and (600) planes, respectively [20]. All these signals matched those indexed for this MOF from its crystallographic data (CCDC 733458) and no impurities were detected, such as benzenedicarboxylic acid. Afterward, the compatibility 
between the decomposition temperatures of the metal precursors and the MOF was analyzed by TGA, both in an inert and in air atmosphere. During the impregnation process, the transition metals were incorporated as nitrate salts onto the UiO-66 surface. Afterward, the nitrate ion decomposition was required to obtain the metal oxides. In this context, it is necessary to analyze the atmosphere and temperature condition in which this decomposition was done, maintaining the MOF structure. Figure 1a, profile 3, presents the TGA of UiO-66 in inert gas, and Figure 1b, profile 3, depicts its corresponding derivative TGA (dTGA). Typical evolutions were observed, with an initial mass loss up to $130{ }^{\circ} \mathrm{C}$ due to physisorbed water and/or residual solvent of synthesis. Then, another small mass loss from $180{ }^{\circ} \mathrm{C}$ due to the dehydroxylation of the inorganic cluster of the MOF from $\mathrm{Zr}_{6} \mathrm{O}_{4}(\mathrm{OH})_{4}$ to $\mathrm{Zr}_{6} \mathrm{O}_{6}$. Finally, the thermal decomposition of the ligands was observed, which was similar to the one corresponding to this MOF synthesized under conventional conditions [26], with a maximum decomposition rate $\left(\mathrm{T}^{\mathrm{max}}\right)$ at $555^{\circ} \mathrm{C}$ (Figure $1(\mathrm{~b} 3)$ and Table 1). Instead, under air atmosphere, the TGA (Figure 1(c3)) and dTGA profiles (Figure 1(d3)) showed a somewhat lower stability with a $\mathrm{T}^{\mathrm{max}}$ of $520^{\circ} \mathrm{C}$ (Table 1). This evolution was more exothermic compared to the previous one as could be seen in the SDTA (Figure S2, Supplementary Materials). Meanwhile, the copper precursor showed a complete decomposition at $290^{\circ} \mathrm{C}$ or $265^{\circ} \mathrm{C}$ in inert gas (Figure 1(a4)) or air (Figure 1(b4)), respectively. The degradation temperature window of the MOF and the precursor suggested the possibility of obtaining dispersed copper species by applying heat treatments.

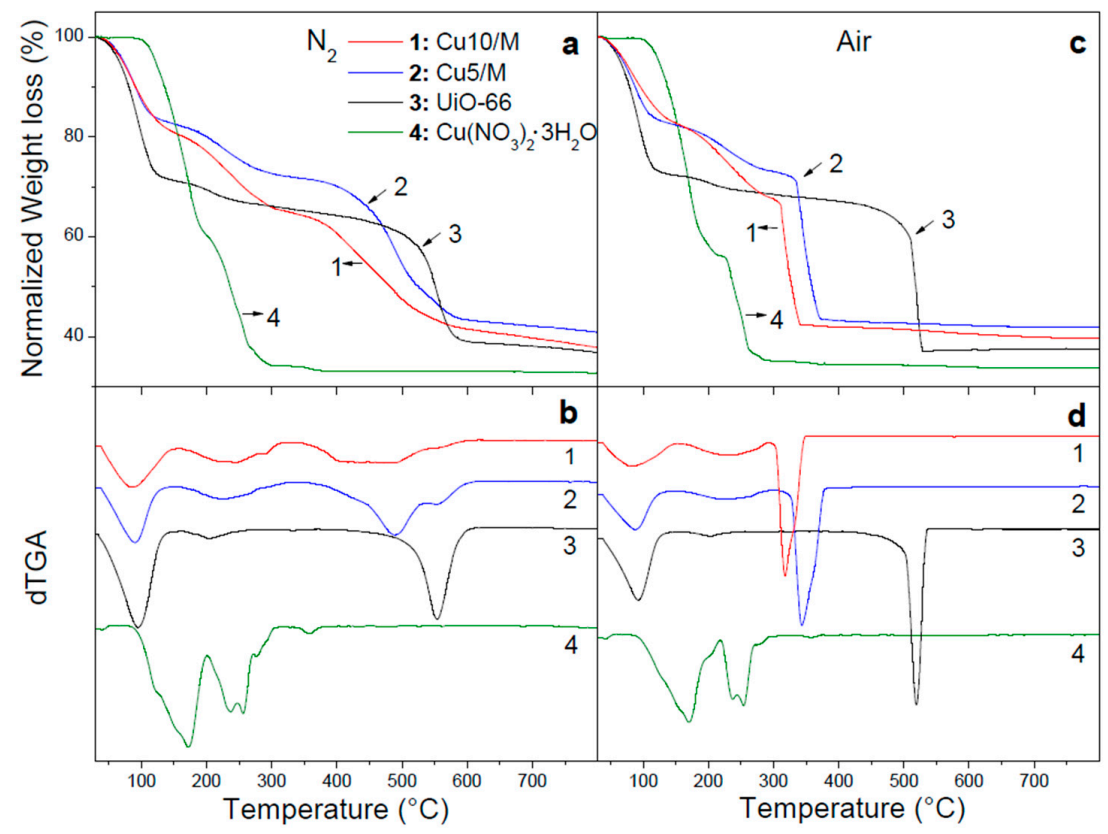

Figure 1. Thermogravimetric analysis (TGA) of UiO-66 (M), Cu/M, and copper precursor: (a) $\mathrm{N}_{2}$ atmosphere; (c) air atmosphere. Corresponding derivative TGA (dTGA) curves: (b) $\mathrm{N}_{2}$ atmosphere; (d) air atmosphere.

Table 1. Maximum decomposition temperatures $\left(\mathrm{T}^{\mathrm{max}}\right)$ of the fresh metal-organic framework (MOF) and of the MOF impregnated with copper $(\mathrm{Cu} / \mathrm{M})$ and that of the respective metal precursors (obtained from the derivative thermogravimetric analysis (dTGA) data).

\begin{tabular}{ccc}
\hline & $\mathbf{T}^{\text {max }} \mathbf{N}_{\mathbf{2}}{ }^{\mathbf{1}}$ & $\mathbf{T}^{\text {max }}$ Air $^{\mathbf{2}}$ \\
\hline $\mathrm{Cu}\left(\mathrm{NO}_{3}\right)_{2} \cdot 3 \mathrm{H}_{2} \mathrm{O}$ & 259 & 255 \\
$\mathrm{UiO}-66$ & 555 & 520 \\
$\mathrm{Cu}_{5} / \mathrm{UiO}-66$ & 490 & 346 \\
$\mathrm{Cu}_{10} / \mathrm{UiO}-66$ & 460 & 318 \\
\hline
\end{tabular}

${ }^{1}$ Decomposition temperature $\left({ }^{\circ} \mathrm{C}\right)$ of the maximum in the $\mathrm{N}_{2}$ dTGA profile. ${ }^{2}$ Decomposition temperature $\left({ }^{\circ} \mathrm{C}\right)$ of the maximum in the air dTGA profile. 
The MOF impregnated with 5 wt.\% copper $\left(\mathrm{Cu}_{5} / \mathrm{M}\right)$ showed a marked decrease in the structural stability of the framework (Figure $1 \mathrm{a}, \mathrm{b}$ ), which was magnified with a higher copper amount $(\mathrm{Cu} 10 / \mathrm{M})$. The $\mathrm{T}^{\mathrm{max}}$ was reduced from $555{ }^{\circ} \mathrm{C}$ to $490{ }^{\circ} \mathrm{C}$ and $460{ }^{\circ} \mathrm{C}$ for fresh UiO-66, $\mathrm{Cu}_{5} / \mathrm{M}$, and $\mathrm{Cu} 10 / \mathrm{M}$, respectively (Table 1 ). The same effect was observed in air but with a greater destabilization of the framework. This phenomenon is attributed to the copper species formed after the precursor decomposition, which catalyzed the oxidation of the organic part of the MOF, accelerating its structural collapse. However, a small temperature gap persisted in which it would be possible to decompose the said precursor before the MOF collapsed. The SDTA of $\mathrm{Cu} / \mathrm{M}$ in both atmospheres (Figure S2, Supplementary Materials) showed only an endothermic process due to the evacuation of host molecules that ended at $160^{\circ} \mathrm{C}$, and an exothermic one near $300^{\circ} \mathrm{C}$ due to MOF collapse. From the previous results, pretreatments of $\mathrm{Cu}_{10} / \mathrm{M}$ in inert and combinations with air were carried out at different temperatures prior to carrying out its catalytic test in order to get insight into the catalytic performances and structural stabilities after the different pretreatments.

\subsubsection{Copper-Based UiO-66 Catalysts}

In Figure 2a it can be observed that $\mathrm{UiO}-66$ by itself presented no activity in the oxidation of $\mathrm{CO}$. On the other hand, $\mathrm{Cu}_{10} / \mathrm{M}$ treated for $1 \mathrm{~h}$ at $200{ }^{\circ} \mathrm{C}$ in $\mathrm{He}(1)$ presented activity, reaching a maximum conversion of $60 \%$ at the said temperature, while a treatment at $225^{\circ} \mathrm{C}$ (2) yielded an improvement, reaching conversions of $75 \%$. Meanwhile, a pretreatment at $300{ }^{\circ} \mathrm{C}$ impaired activity, as observed in solid (3). The diffractograms of these evaluated samples (Figure 2b) indicate that samples (1) and (2) maintained the MOF structure. Nevertheless, a degradation of the MOF took place in sample (3). The absence of definite signals of copper species in all the diffractograms should be highlighted since it indicates their high dispersion. Accordingly, in solids (1) and (2), the catalytic activity was due to copper species highly dispersed in the MOF structure, while, in sample (3), those species were dispersed in an amorphous solid.

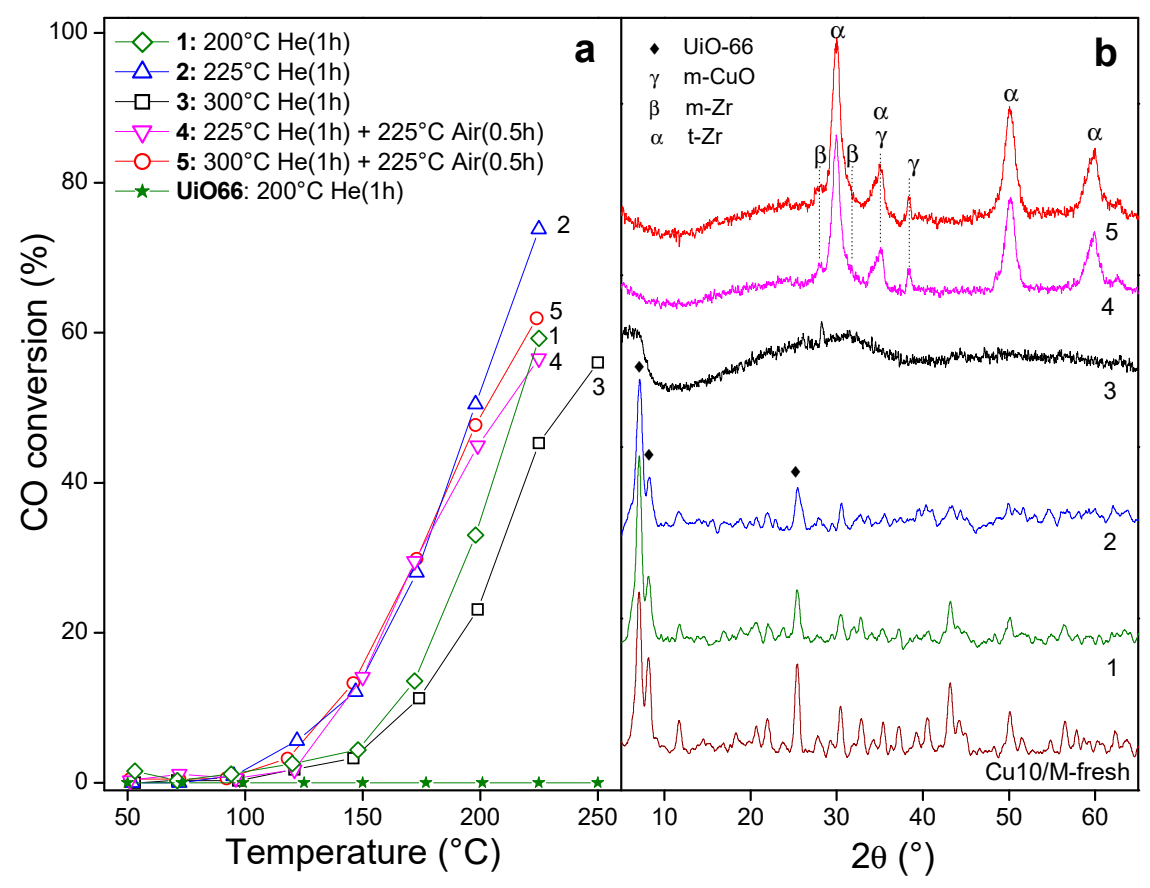

Figure 2. $\mathrm{Cu} / \mathrm{UiO}-66$ solids $(\mathrm{Cu} / \mathrm{M})$ : (a) catalytic evaluation in the $\mathrm{CO}$ oxidation; (b) X-ray diffraction (XRD) patterns after the reaction.

The change in the pretreatment atmosphere was analyzed in terms of the activity of $\mathrm{Cu}_{10} / \mathrm{M}$ by combining the pretreatment in inert atmosphere followed by a brief exposure to air for $0.5 \mathrm{~h}$ (sample (4)). The as-treated solid was also active (Figure 2a) even though the treatment promoted the 
total degradation of the MOF (Figure 2b), favoring its evolution to a crystalline phase of tetragonal zirconia (t-Zr), (JCPDS 17-923). The decomposition of the hydrated nitrate salts in the presence of air can generate various oxidizing agents such as $\mathrm{HNO}_{3}$ and $\mathrm{NO}_{2}$, which, added to the treatment in oxygen, can give rise to a hyperoxidizing atmosphere and accelerate the transformation of the MOF into zirconia. This evolution is in agreement with what was reported for the decomposition of UiO-66 in air [27]. A high dispersion of cupric oxide was observed in these solids, characterized by weak signals at $2 \theta=35.5^{\circ}$ (masked by a signal of $\mathrm{t}-\mathrm{Zr}$ ) and $38.5^{\circ}$, corresponding to the (11-1) and (111) planes of a $\mathrm{CuO}$ monoclinic phase (JCPDS 48-1548), respectively.

The TEM image of the synthesized MOF shows nanometric crystals with sizes ranging from 30-100 nm which formed globular aggregates (Figure 3a), making it possible to distinguish the facets of the individual crystals with a polyhedral morphology (Figure 3b) similar to that reported for this MOF but obtained under conventional conditions [20]. Meanwhile, when the said crystals were functionalized with copper following the sequence of impregnation and heat treatment in He to obtain $\mathrm{Cu} / \mathrm{UiO}-66$, the porous structure of the MOF was maintained (Figure 3c). The high-resolution (HR) TEM image showed the characteristic aspect of a porous material but no particles could be distinguished inside the MOF porosity (Figure 3d). This highlights the small size of these copper species dispersed in the MOF, consistent with the XRD results.

In brief, a pretreatment of $\mathrm{Cu}_{10} / \mathrm{M}$ in He for $1 \mathrm{~h}$ at $225^{\circ} \mathrm{C}$ allowed obtaining an active catalyst in the $\mathrm{CO}$ oxidation, based on copper species with high dispersion in the MOF structure which were preserved after the tests in reaction. This nanocatalyst represents a new alternative not only for this reaction but also for other reactions demanding a high dispersion of active copper phases and led at relatively low temperatures $\left(<225^{\circ} \mathrm{C}\right)$. These reactions could be, for example, the reduction of $\mathrm{C}-\mathrm{C}$ multiple bonds and carbonyl, the hydroxylation of benzene, the reduction of aromatic nitrocompounds or $\mathrm{NO}_{x}$ [28], or the synthesis of methanol from $\mathrm{CO}$ and $\mathrm{H}_{2}$ [29].
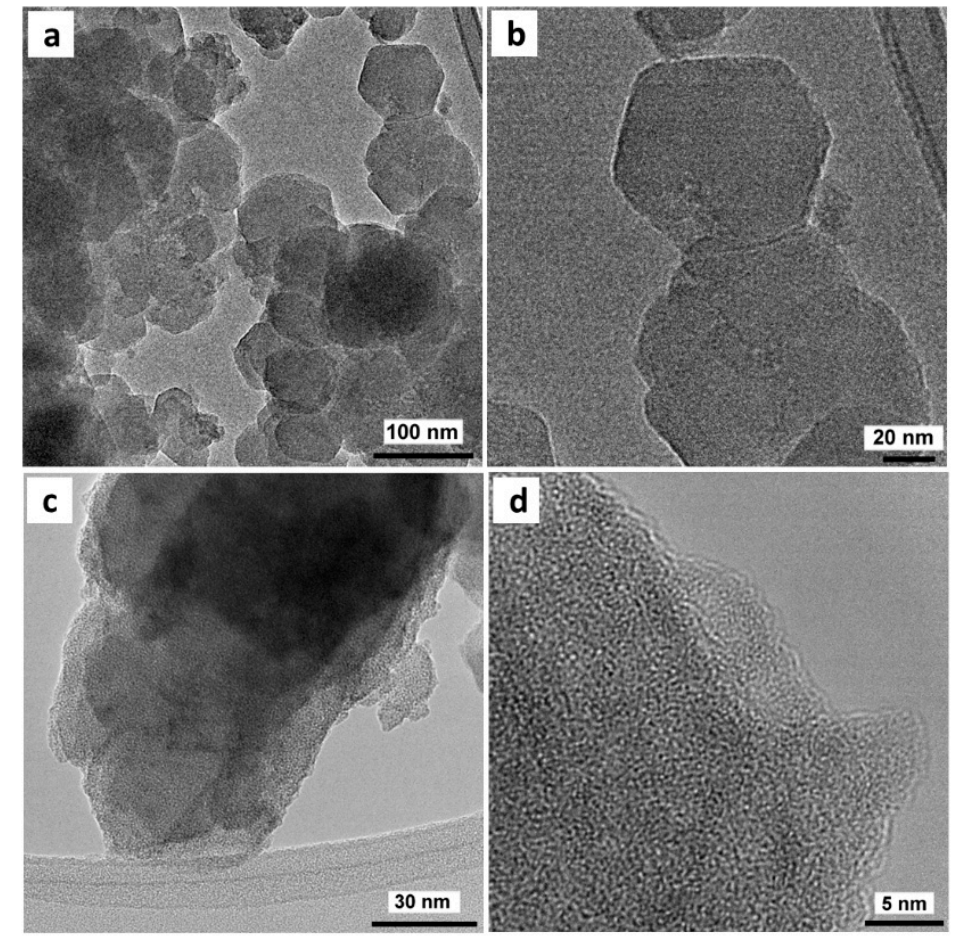

Figure 3. TEM images: (a) as-synthesized UiO-66 crystals; (b) close view of UiO-66; (c) $\mathrm{Cu} / \mathrm{UiO}-66$ catalyst with $\mathrm{He}$ treatment at $225^{\circ} \mathrm{C}$; (d) close view of activated (He treated) $\mathrm{Cu} / \mathrm{UiO}-66$. 


\subsection{Derived Cu/UiO-66 Catalysts}

\subsubsection{Monitoring of the Thermal Transformation of $\mathrm{Cu} / \mathrm{MOF}$}

Given the structural changes observed after the thermal pretreatments, the transformation of $\mathrm{Cu} / \mathrm{M}$ was analyzed through temperature-programmed X-ray diffraction (T-XRD) both in an inert atmosphere and in air. In the first case, from $250^{\circ} \mathrm{C}$, the MOF underwent a reduction in crystallinity (Figure 4a), totally losing itself at $325{ }^{\circ} \mathrm{C}$ (red curve). Then, the solid persisted as an amorphous material in which signals at $43.3^{\circ}$ and $50.1^{\circ}$ emerged (the latter masked with a t-Zr signal), which corresponded to the (111) and (200) planes of a cubic $\mathrm{Cu}^{0}$ phase, respectively (JCPDS 4-836). At higher temperatures, these species increased the crystallinity, while the support evolved into a tetragonal zirconia $(\mathrm{t}-\mathrm{Zr}$ ) of low crystallinity. This is consistent with what was discussed above. On the other hand, heat treatments in air showed that the structure of the MOF was more unstable (Figure 4b) losing the crystallinity at $275{ }^{\circ} \mathrm{C}$ (red curve). In addition, it quickly transformed into a t-Zr system with a high dispersion of copper oxide species. The stable formation of a $\mathrm{t}-\mathrm{Zr}$ phase from this MOF was attributed to the initial transformation of the small zirconia nuclei from inorganic nodes, which have a low surface energy and facilitate the evolution toward a tetragonal phase instead of a monoclinic $\left(\mathrm{m}-\mathrm{Zr}\right.$ ) [27]. From about $400{ }^{\circ} \mathrm{C}$ a small contribution of $\mathrm{m}-\mathrm{Zr}$ was detected, characterized by strong signals at $2 \theta=27.9^{\circ}, 31.2^{\circ}, 34.1^{\circ}, 40.7^{\circ}$, and $49.1^{\circ}$, corresponding to the $(-111),(111),(200),(-112)$, and (220) planes, respectively (JCPDS 37-1484). An increase in the proportion of the monoclinic phase in copper-doped zirconia was attributed to copper inclusion in the $\mathrm{ZrO}_{2}$ network, which increased the size of the crystallites, causing a growth in the free surface energy and, thus, promoting the evolution toward $\mathrm{m}-\mathrm{ZrO}_{2}$ [30]. This could be, in our case, due to a migration of part of the copper to the zirconia phase in formation during the heat treatment in air.

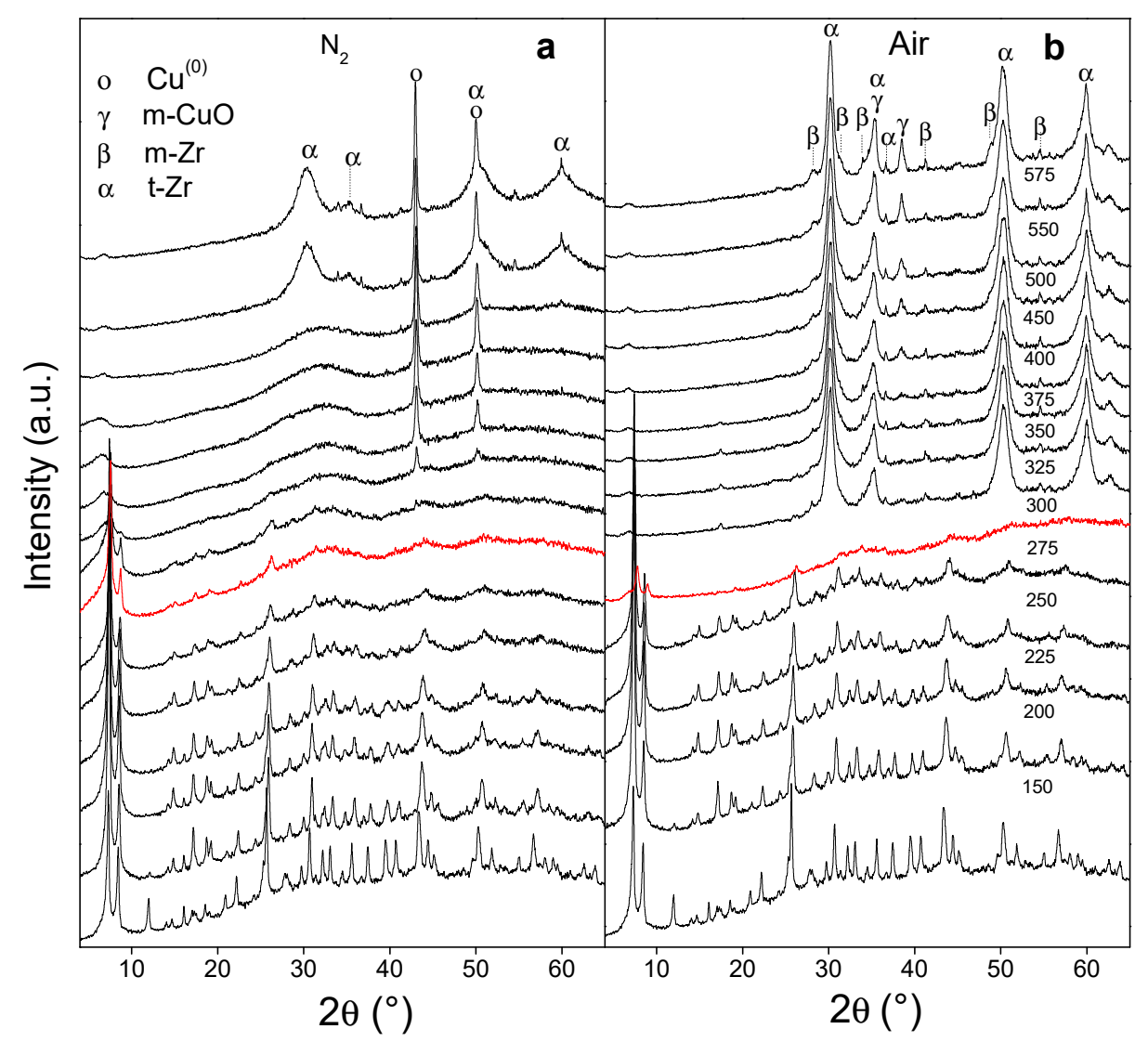

Figure 4. Analyses of X-ray diffraction at programmed temperature (T-XRD) with the Cu/M sample: (a) in nitrogen; (b) in air. 
By T-XRD, it was shown that thermal pretreatments of the $\mathrm{Cu} / \mathrm{M}$ solid in an inert atmosphere caused a delayed degradation of the MOF toward an amorphous solid in which $\mathrm{Cu}^{0}$ species evolved. Meanwhile, the MOF degradation was accelerated in air with a fast growth of $\mathrm{t}-\mathrm{Zr}$ phase with a small contribution of $\mathrm{m}-\mathrm{Zr}$ and with highly dispersed $\mathrm{CuO}$ species. Given the potential of solids derived from $\mathrm{Cu} / \mathrm{M}$, their catalytic behavior was analyzed.

\subsubsection{Catalytic Behavior of Derived $\mathrm{Cu} / \mathrm{UiO}-66$ Catalysts}

$\mathrm{Cu}_{10} / \mathrm{M}$ was pretreated in situ in He flow at $225^{\circ} \mathrm{C}$ for $1 \mathrm{~h}$, and its catalytic curve showed an inflection in the profile starting at $250{ }^{\circ} \mathrm{C}$ (Figure 5a) due to a fall in the CO conversion. This was caused by a smaller availability of oxygen for the reaction (as observed in the insert in Figure 5a), which was consumed in the MOF degradation. Hence, $250{ }^{\circ} \mathrm{C}$ is the maximum temperature at which $\mathrm{Cu}_{10} / \mathrm{M}$ maintained its structure under reaction conditions. From $375^{\circ} \mathrm{C}$ the oxygen was recovered, and the catalyst was taken up to $400{ }^{\circ} \mathrm{C}$ for $1 \mathrm{~h}$ in reaction, maintaining conversions of $100 \%$; later, the catalyst was cooled and evaluated again. In this case, $\mathrm{Cu}_{23} / \mathrm{Zr}(1)$, a marked activation was observed (Figure 5a) due to the evolution of the solid to the system of copper oxide dispersed in a developing $\mathrm{t}$-Zr phase (Figure 5b). Since the zirconia mass in the derived solid was around $37.4 \mathrm{wt} . \%$ with respect to the initial mass of the MOF, the proportion of copper in these systems was $23 \mathrm{wt} . \%$. It is noticeable that, with this high load, the copper species were highly dispersed in the t-Zr support. Given the good catalytic performance of these solids and taking into account the studies of the transformation of a $\mathrm{Cu} / \mathrm{M}$ solid into $\mathrm{Cu} / \mathrm{Zr}$, a pretreatment of $\mathrm{Cu}_{10} / \mathrm{M}$ in air was performed at $400{ }^{\circ} \mathrm{C}$ for $2 \mathrm{~h}$. In this case, $\mathrm{Cu}_{23} / \mathrm{Zr}(2)$, a remarkable shift of the catalytic curves was observed, reaching total conversion at $225{ }^{\circ} \mathrm{C}$ (Figure 5a) without extra oxygen consumption due to the presence of a stabilized phase of $\mathrm{CuO} / \mathrm{ZrO}_{2}$ (Figure $5 \mathrm{~b}$ ) with a contribution of a m-Zr phase. Compared with classical $\mathrm{CuO} / \mathrm{ZrO} 2$ catalysts obtained via other techniques such as sol-gel [31] or urea combustion [32], the use of the MOF as a template allowed minimizing the generation of bulk $\mathrm{CuO}$ of low interaction with zirconia, which would generate a lower catalytic activity. In contrast to the MOF-derived zirconia (Zr in Figure 5b), the $\mathrm{Cu}_{23} / \mathrm{Zr}(2)$ solid showed a contribution of the $\mathrm{m}-\mathrm{Zr}$ phase. When $\mathrm{Cu}_{10} / \mathrm{M}$ was pretreated in air at $500{ }^{\circ} \mathrm{C}, \mathrm{Cu}_{23} / \mathrm{Zr}$ (3), a slight catalytic improvement was observed with respect to the former case, reaching total conversion at $175^{\circ} \mathrm{C}$.

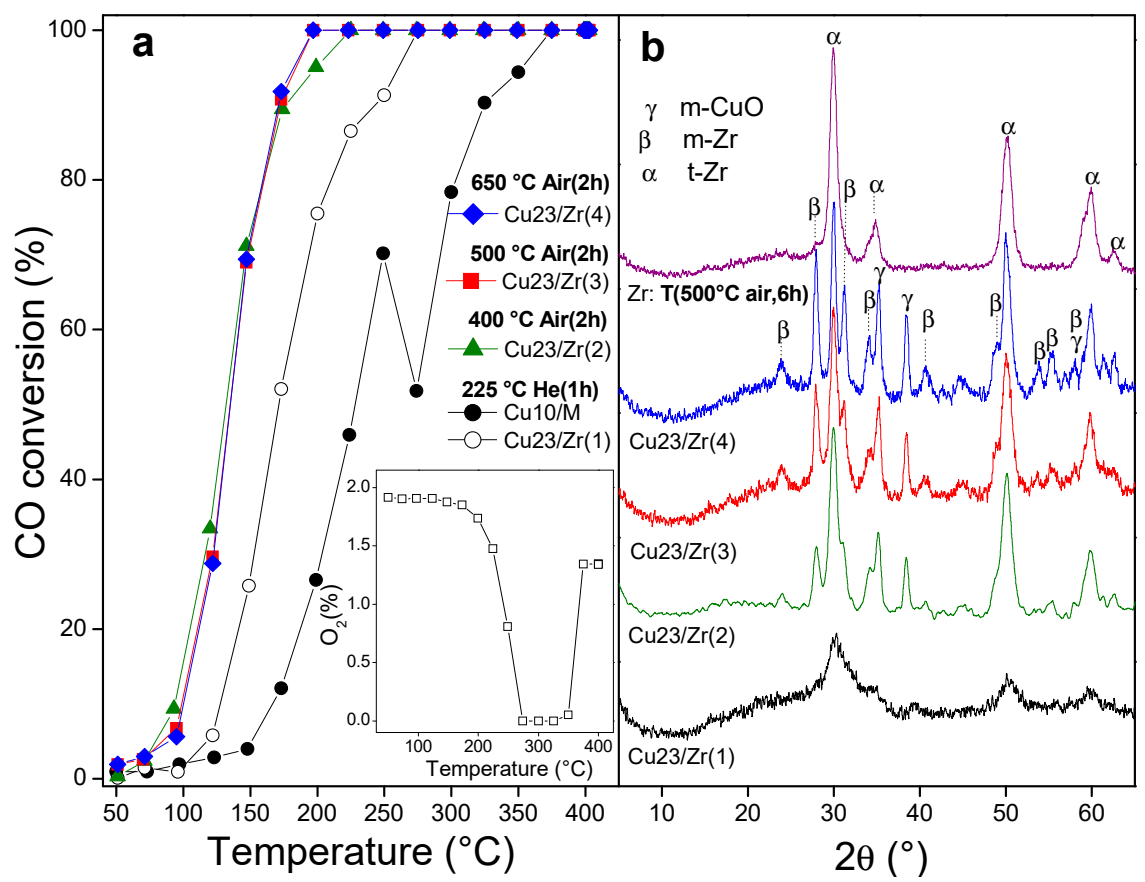

Figure 5. $\mathrm{Cu} / \mathrm{UiO}-66-$ derived solids: (a) catalytic evaluation; (b) XRD patterns after reaction. 
However, the contribution of $\mathrm{m}-\mathrm{Zr}$ in this sample was more evident, which could be related to its better catalytic behavior. In this sense, it was demonstrated that the adsorption capacity of $\mathrm{CO}$ in $\mathrm{m}-\mathrm{Zr}$ supports was higher than in $\mathrm{t}-\mathrm{Zr}$, which can be explained by a higher Lewis acidity $\left(\mathrm{Zr}^{4+}\right)$, as well as a higher Lewis basicity $\left(\mathrm{O}^{2-}\right)$, on the surface of the $\mathrm{m}-\mathrm{Zr}$ solid [33]. Finally, a pretreatment at $650{ }^{\circ} \mathrm{C}$ in air, $\mathrm{Cu}_{23} / \mathrm{Zr}(4)$, did not improve the conversion (Figure 5a), even though it favored the development of the monoclinic phase, probably due to a sintering of the $\mathrm{CuO}$ species (Figure $5 \mathrm{~b}$ ).

\subsection{Derived Cobalt and Iron-Based UiO-66 Catalysts}

Other non-noble metals of interest that have activity in the $\mathrm{CO}$ oxidation reaction are cobalt and iron [13], added to the fact that the latter is a very low-cost metal with high abundance. The decomposition temperature of cobalt and iron nitrate precursors in air was far from the limit of MOF stability (Table 2, Figure S3, Supplementary Materials) while the incorporation of $10 \mathrm{wt.} \%$ Co or $\mathrm{Fe}$ in the $\mathrm{MOF}\left(\mathrm{Co}_{10} / \mathrm{M}, \mathrm{Fe}_{10} / \mathrm{M}\right)$ decreased the framework stability due to the formed oxides, although the shift was lower than that of $\mathrm{Cu}_{10} / \mathrm{M}$. The order of structural stability was as follows: $\mathrm{Co} / \mathrm{M}>\mathrm{Fe} / \mathrm{M}$ $>\mathrm{Cu} / \mathrm{M}$. The SDTA profiles in air (Figure S3, Supplementary Materials) were very similar to that of $\mathrm{Cu}_{10} / \mathrm{M}$, with an endothermic peak due to the evaporation of host molecules and an exothermic one due to structural collapse. Taking into account the similar structure stability of $\mathrm{Cu}_{10} / \mathrm{M}$ under either He or air atmosphere at temperatures lower than $275^{\circ} \mathrm{C}, \mathrm{Co}_{10} / \mathrm{M}$ and $\mathrm{Fe}_{10} / \mathrm{M}$ solids were pretreated at $250^{\circ} \mathrm{C}$ in air, and their catalytic behavior was analyzed.

Table 2. Maximum decomposition temperatures ( $\mathrm{T}^{\mathrm{max}}$ ) of the MOF impregnated with cobalt (Co/UiO-66) and iron (Fe/UiO-66), and that of the respective metal precursors (obtained from the dTGA data in air).

\begin{tabular}{cc}
\hline & T $^{\text {max }}$ Air $^{\mathbf{1}}$ \\
\hline $\mathrm{Co}\left(\mathrm{NO}_{3}\right)_{2} \cdot 6 \mathrm{H}_{2} \mathrm{O}$ & 263 \\
$\mathrm{Fe}\left(\mathrm{NO}_{3}\right)_{3} \cdot 9 \mathrm{H}_{2} \mathrm{O}$ & 163 \\
$\mathrm{Co}_{10} / \mathrm{UiO}-66$ & 465 \\
$\mathrm{Fe}_{10} / \mathrm{UiO}-66$ & 435 \\
\hline
\end{tabular}

For the $\mathrm{Co}_{10} / \mathrm{M}$ solid (Figure S4a, Supplementary Materials), from $200{ }^{\circ} \mathrm{C}$ onward, conversion increased proportionally with temperature, and, when it was over $325^{\circ} \mathrm{C}$, both a conversion fall and an abrupt consumption of oxygen were produced due to the MOF degradation. The activity evolved until total conversion but at a higher temperature than the $\mathrm{Cu}_{10} / \mathrm{M}$ solid, previously analyzed. Subsequently, this solid was taken to $400^{\circ} \mathrm{C}$ and was kept $1 \mathrm{~h}$ under reaction. When evaluated again, an improvement in activity was observed, $\mathrm{Co}_{23} / \mathrm{Zr}$ (1). The catalyst consisted of a $\mathrm{t}-\mathrm{Zr}$ phase evolving with a high dispersion of cobalt species due to the absence of characteristic signals of their oxides (Figure S4b, Supplementary Materials). Since it was observed that an improvement in $\mathrm{ZrO}_{2}$ crystallinity favored the activity, a pretreatment of the $\mathrm{Co}_{10} / \mathrm{M}$ sample was performed in air but at $400{ }^{\circ} \mathrm{C}$ for $2 \mathrm{~h}$. This effectively improved the catalytic performance (Figure S4a, Supplementary Materials) due to the formation of a stabilized phase of $\mathrm{Co}_{3} \mathrm{O}_{4}$ in a $\mathrm{t}-\mathrm{Zr}$ of high crystallinity (Figure $\mathrm{S} 4 \mathrm{~b}$, Supplementary Materials). This is in agreement with what was reported regarding the formation of this cubic spinel (JPDS 43-1003) on conventional $\mathrm{ZrO}_{2}$ supports [15].

On the other hand, $\mathrm{Fe}_{10} / \mathrm{M}$ showed less activity (Figure S4a, Supplementary Materials), even over $300{ }^{\circ} \mathrm{C}$ when the MOF decomposed. After $1 \mathrm{~h}$ in reaction at $400{ }^{\circ} \mathrm{C}$, the system was evaluated again, and an improvement was observed even though total conversion was not reached in the temperature range analyzed. This solid consisted of an incipiently formed $\mathrm{t}-\mathrm{Zr}$ with a high dispersion of iron species (Figure S4b, Supplementary Materials). In this case, a remarkable catalytic improvement was also observed when pretreating at $400{ }^{\circ} \mathrm{C}$ in air. This solid consisted of a highly crystalline $\mathrm{t}-\mathrm{Zr}$ with a small contribution of $\mathrm{m}-\mathrm{Zr}$ which dispersed a rhombohedral hematite phase $\left(\alpha-\mathrm{Fe}_{2} \mathrm{O}_{3}\right)$. The previous confinement of the iron precursor in the pores of UiO-66 facilitated, after degradation, the generation 
of small $\mathrm{Fe}_{2} \mathrm{O}_{3}$ crystals that were quite active in $\mathrm{CO}$ oxidation, as already observed for iron oxide crystals [34].

The MOF degradation under reaction conditions of $\mathrm{CO}$ oxidation started at 325,300 , and $250{ }^{\circ} \mathrm{C}$ for $\mathrm{Co}_{10} / \mathrm{M}, \mathrm{Fe}_{10} / \mathrm{M}$, and $\mathrm{Cu}_{10} / \mathrm{M}$ respectively. Although the thermal stability of the latter was slightly lower, its $\mathrm{CO}$ conversion at $250{ }^{\circ} \mathrm{C}$ was significantly higher (70\%) than that of the other two samples $(17 \%$ and $5 \%$ ). The best catalytic performance corresponded to the $\mathrm{Cu}$-based sample after the degradation of the MOF structure in air at $400{ }^{\circ} \mathrm{C}$ for $2 \mathrm{~h}\left(\mathrm{Cu}_{23} / \mathrm{Zr}\right)$, which reached $100 \% \mathrm{CO}$ conversion at $225{ }^{\circ} \mathrm{C}$. At that temperature, the conversion for the $\mathrm{Co}_{23} / \mathrm{Zr}$ solid was $45 \%$, while, for the $\mathrm{Fe}_{23} / \mathrm{Zr}$ solid, it was only $8 \%$.

\subsection{Bimetallic $\mathrm{CuCo/UiO-66-and} \mathrm{CuFe/UiO-66-Derived} \mathrm{Nanocatalysts}$}

\subsubsection{CO Oxidation}

It was reported that mixed cobalt and copper oxides [35], as well as copper-iron mixed oxides synthesized by low-temperature co-precipitation methods [33,36,37], have synergistic effects on the oxidation of $\mathrm{CO}$; therefore, bimetallic systems were prepared incorporating these metals into UiO-66. The solids obtained by successive impregnation were analyzed, firstly by incorporating the copper precursor followed by their thermal treatment $\left(500^{\circ} \mathrm{C}\right.$, air, $\left.2 \mathrm{~h}\right)$; subsequently, a cobalt or iron precursor was added, followed by a final calcination step in air $\left(400{ }^{\circ} \mathrm{C}, 2 \mathrm{~h}\right)$ to obtain $\mathrm{Cu}_{16} \mathrm{Co}_{7} / \mathrm{Zr}$ and $\mathrm{Cu}_{16} \mathrm{Fe}_{7} / \mathrm{Zr}$ systems. The $\mathrm{Cu}_{16} / \mathrm{Zr}, \mathrm{Cu}_{16} \mathrm{Co}_{7} / \mathrm{Zr}$, and $\mathrm{Cu}_{16} \mathrm{Fe}_{7} / \mathrm{Zr}$ samples exhibited well-developed $\mathrm{t}-\mathrm{Zr}$ phases with a small contribution of $\mathrm{m}-\mathrm{Zr}$ (promoted by the presence of copper as discussed above), adding to a $\mathrm{CuO}$ phase with high dispersion (Figure 6). Additionally, a $\mathrm{Co}_{3} \mathrm{O}_{4}$ phase was observed in the solid containing cobalt, while, in the iron-containing bimetallic solid, no iron oxide phases were detected. This accounts for the high dispersion of the FeO phases in this solid. The catalytic assays showed that, among these catalysts, an improvement in the activity of $\mathrm{Cu}_{16} \mathrm{Fe}_{7} / \mathrm{Zr}$ was found (Figure $6 \mathrm{a}$ ). This was due to both the initial presence of a very small proportion of $\mathrm{m}-\mathrm{Zr}$ phase before the incorporation of iron and the subsequent development of a Fe-Cu synergy among these species due to their intimate contact, favored by the high dispersion achieved by these oxides in the solid, as shown by their XRD patterns.

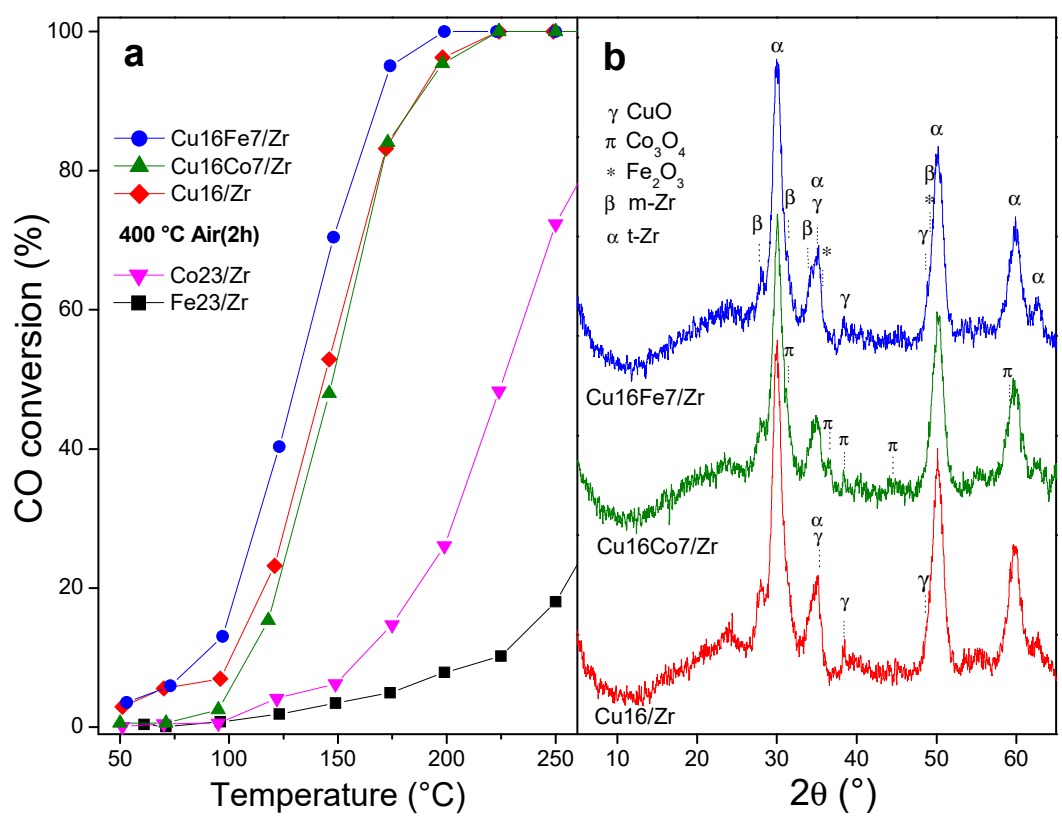

Figure 6. $\mathrm{CuCo} / \mathrm{Zr}$ and $\mathrm{CuFe} / \mathrm{Zr}$ nanocatalysts: (a) catalytic behavior; (b) XRD patterns after reaction.

The catalytically evaluated nanomaterials were analyzed by laser Raman spectroscopy (LRS). These spectra are shown in Figure 7, and the respective spectra of the used monometallic samples are included for comparison. The vibrational signals observed in all of these spectra are consistent with 
the crystalline phases identified by $X R D$. The vibrations of the monoclinic $\mathrm{ZrO}_{2}(\mathrm{~m}-\mathrm{Zr})$ and tetragonal $\mathrm{ZrO}_{2}(\mathrm{t}-\mathrm{Zr})$ phases were present in the $\mathrm{Cu}_{16} / \mathrm{Zr}$ spectrum (Figure 7), proving the existence of both zirconia phases. The characteristic narrow vibration signals of $\mathrm{m}$-Zr were at 179, 192, 335, 347, 385, 476,614 , and $635 \mathrm{~cm}^{-1}$, with that at $476 \mathrm{~cm}^{-1}$ being the strongest one [15], while the typical broad signals of $\mathrm{t}-\mathrm{Zr}$ were at $145,275,310,460$, and $650 \mathrm{~cm}^{-1}$ [27]. In the case of the sample with higher copper content, $\mathrm{Cu}_{23} / \mathrm{Zr}$, the monoclinic phase was clearly identified due to its narrow vibration signals (Figure 7). The vibrations of $\mathrm{CuO}$ at 280, 335, and $615 \mathrm{~cm}^{-1}$ [8] overlapped with those of the zirconia, thus hindering their identification. The spectrum of $\mathrm{Co}_{23} / \mathrm{Zr}$ pointed out the existence of a $\mathrm{t}-\mathrm{ZrO}{ }_{2}$ phase and a $\mathrm{Co}_{3} \mathrm{O}_{4}$ spinel $\left(485,523\right.$, and $\left.687 \mathrm{~cm}^{-1}\right)$ [15], in clear agreement with the XRD results. The absence of $\mathrm{m}-\mathrm{ZrO}_{2}$ was evident, inferring that the UiO-66 degradation in the presence of cobalt hampered the formation of this monoclinic phase. The same outcome was obtained when iron was the impregnated metal. The $\mathrm{Fe}_{23} / \mathrm{Zr}$ spectrum (Figure 7) revealed the presence of just $\mathrm{t}-\mathrm{ZrO}_{2}$ and $\alpha-\mathrm{Fe}_{2} \mathrm{O}_{3}(226,246,293$, 411 , and $\left.610 \mathrm{~cm}^{-1}[36]\right)$, and no signals of $\mathrm{m}-\mathrm{ZrO}_{2}$ were identified.

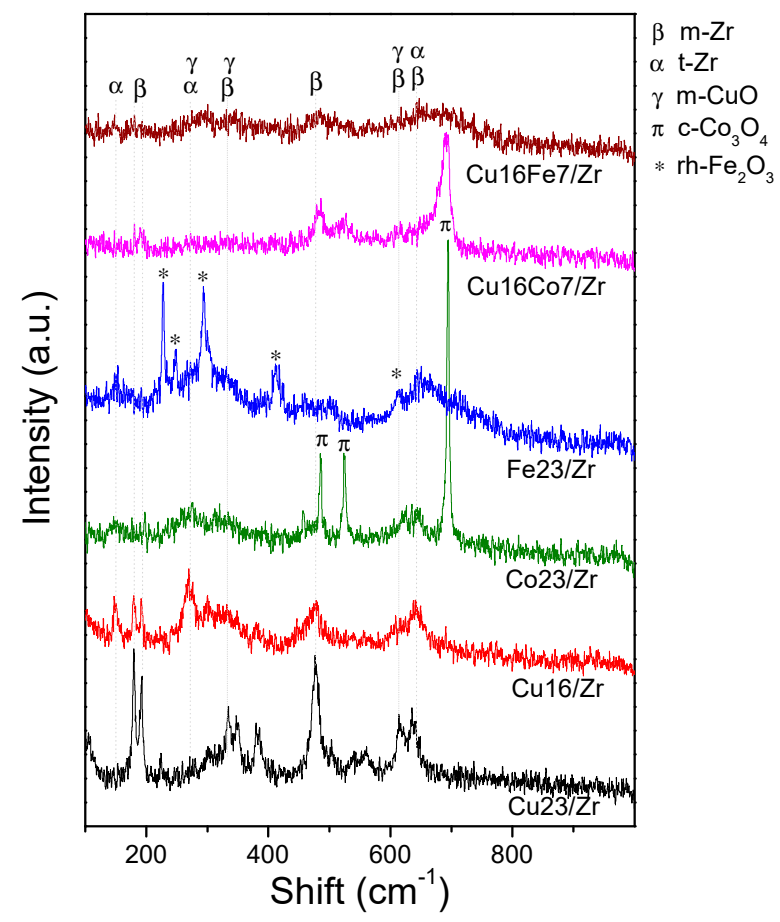

Figure 7. Laser Raman spectroscopy (LRS) spectra of the mono and bimetallic solids after the CO oxidation reaction.

In the spectra of the bimetallic catalysts, it could be observed that the zirconia signals were mainly associated with $\mathrm{t}-\mathrm{Zr}$ (Figure 7). In the $\mathrm{Cu}_{16} \mathrm{Fe}_{7} / \mathrm{Zr}$ sample, a high dispersion of iron and copper oxides was achieved given the absence of defined signals of these phases, in line with what was observed by $X R D$ and also confirming the absence of agglomerates after the reaction. This shows that the addition of $\mathrm{Fe}$ to the $\mathrm{Cu} / \mathrm{Zr}$ system generated highly dispersed and stable iron species, since they were kept in that situation in the solid after reaction (Figure 7). This is in contrast with the higher sintering reached in the monometallic $\mathrm{Fe} / \mathrm{Zr}$ system after reaction. On the other hand, in the spectrum of sample $\mathrm{Cu}_{16} \mathrm{Co}_{7} / \mathrm{Zr}$, the signals of a developed $\mathrm{Co}_{3} \mathrm{O}_{4}$ spinel were dominant (Figure 7), in agreement with XRD observations, showing again that the cobalt species were segregated forming big crystals at the catalyst surface.

The bimetallic sample $\mathrm{Cu}_{16} \mathrm{Fe}_{7} / \mathrm{Zr}$ exhibited a nanoparticle system in intimate contact (Figure 8a), confirming the results of XRD and LRS discussed above, which corresponded to small domains of zirconia phases and oxides of copper and iron. The different crystalline planes of these phases in the individual crystals can be observed (Figure $8 \mathrm{a}$ ). Figure $8 \mathrm{~b}$ shows the analysis of the same particle in 
dark-field mode and its nature of aggregated nanoparticles was also highlighted. The elementary mapping performed in STEM mode showed a homogeneous distribution of the zirconium (yellow, Figure 8c), iron (green, Figure 8d), and copper (magenta, Figure 8e) phases in the nanoparticle aggregates, confirming the high dispersion and intimate contact between these nano-oxides. The characterizations performed by XRD, LRS, and TEM demonstrated the small particle size reached by the phases of these oxides in intimate contact with each other, explaining the catalytic synergy in this material, as shown in Figure 6.

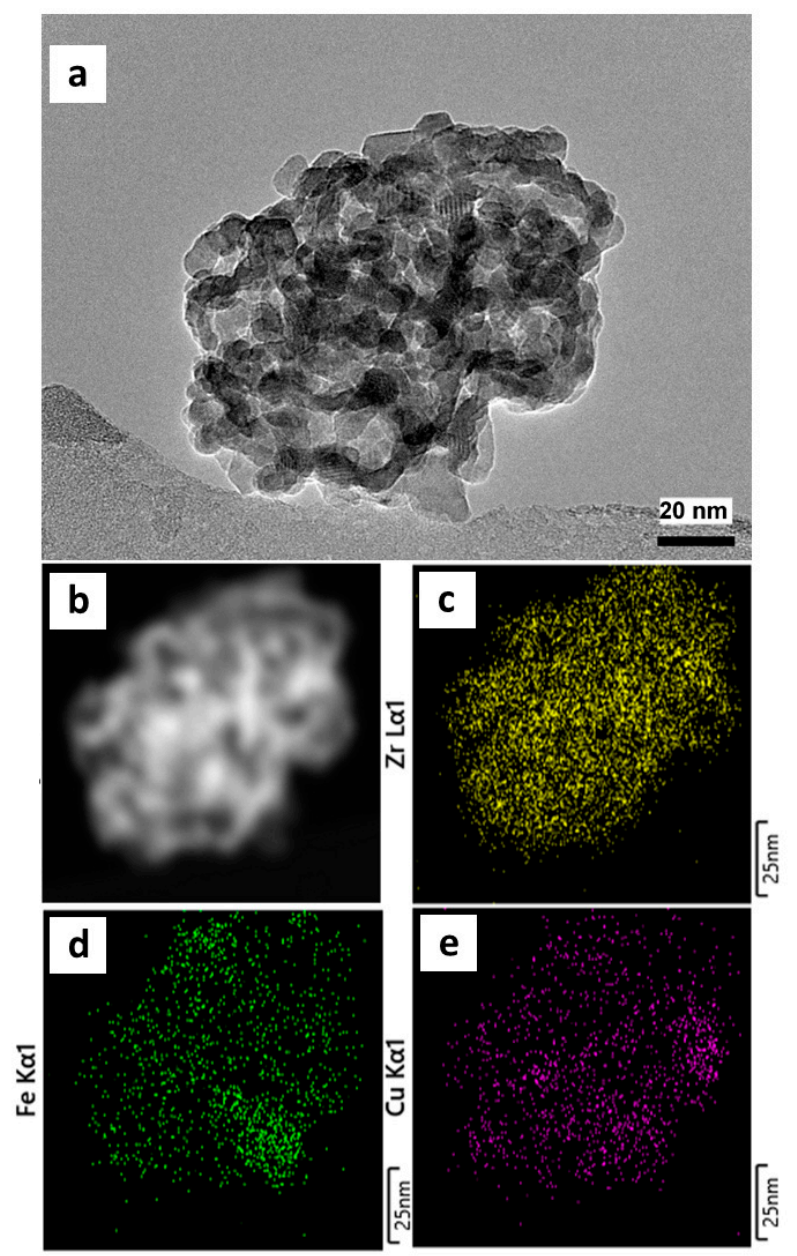

Figure 8. TEM images of $\mathrm{Cu}_{16} \mathrm{Fe}_{7} / \mathrm{Zr}$ catalyst: (a) selected area for the energy-dispersive X-ray (EDX) mapping in bright field; (b) selected area for the EDX mapping in dark field. Elementary mapping: (c) zirconium (yellow); (d) iron (green); (e) copper (magenta).

\subsubsection{CO Oxidation in Hydrogen-Rich Stream (COProx)}

Given the high performance of the $\mathrm{Cu}_{16} / \mathrm{Zr}, \mathrm{Cu}_{16} \mathrm{Co}_{7} / \mathrm{Zr}$ and $\mathrm{Cu}_{16} \mathrm{Fe}_{7} / \mathrm{Zr}$ solids, they were analyzed in the COProx reaction. The conversion curves obtained are presented in Figure $9 \mathrm{a}$ and show a volcano-type shape, similar to that found for catalysts based on these types of dispersed oxides in classical supports $[14,36]$. Initially, the conversion increase may be due to highly dispersed $\mathrm{CuO}$ or superficial $\mathrm{Cu}-\mathrm{O}-\mathrm{Zr}$ type sites on the zirconia [14,32], reaching a maximum of $47 \%\left(175{ }^{\circ} \mathrm{C}\right)$ for the $\mathrm{Cu}_{16} / \mathrm{Zr}$ sample. The fall in conversion at higher temperatures is probably due to a reduction in copper species dispersed in the hydrogen-rich atmosphere [14]. When comparing this behavior with that of the CO oxidation in air (Figure 6), a shift of the curves toward higher temperatures was observed for both the monometallic and bimetallic catalysts. This differs from that observed for dispersed cupric oxide crystals that exhibited a similar activity in both reactions [38], although this behavior was similar to that 
observed for other types of copper-iron mixed oxide catalysts [36]. This change in conversion levels may be due to structural differences between the active sites present and in the reaction mechanism operating under an oxidizing or reductive atmosphere [39]. Meanwhile, the selectivity was greater than $70 \%$ up to $120^{\circ} \mathrm{C}$, after which it fell sharply (Figure $9 \mathrm{~b}$ ).

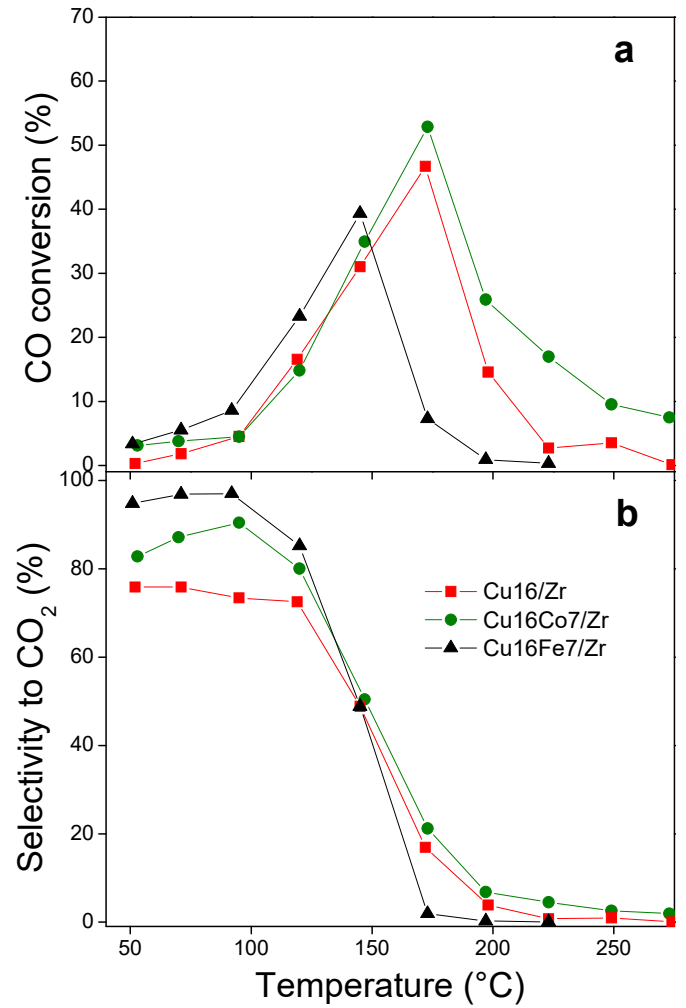

Figure 9. Catalytic evaluations in the preferential $\mathrm{CO}$ oxidation (COProx): (a) CO conversion; (b) selectivity toward $\mathrm{CO}_{2}$.

The $\mathrm{Cu}_{16} \mathrm{Co}_{7} / \mathrm{Zr}$ catalyst exhibited similar characteristics to those analyzed above, with a $53 \%$ maximum conversion at the same temperature. In this sense, $\mathrm{Co}$ and $\mathrm{Cu}$ oxides would compete for the formation of $\mathrm{M}-\mathrm{O}-\mathrm{Zr}$ clusters over the zirconia support and not for the formation of $\mathrm{Cu}-\mathrm{Co}-\mathrm{O}-\mathrm{Zr}$ species that could increase the conversion levels [14]. However, cobalt modulated the activity, given the increase in the selectivity of this system (Figure 9b). At the same time, the $\mathrm{Cu}_{16} \mathrm{Fe}_{7} / \mathrm{Zr}$ solid exhibited a shift of the conversion curve to lower temperature, which was compatible with the higher activity shown by this solid in COTox, previously discussed. Moreover, its selectivity was the highest of all evaluated materials (higher than $85 \%$ up to $125^{\circ} \mathrm{C}$ ). This behavior again accounts for the synergy between the oxide phases in this nanocatalyst.

The LRS characterization of the used catalysts after the COProx evaluation is shown in Figure 10. From the analysis of the $\mathrm{Cu}_{16} / \mathrm{Zr}$ spectra before and after reaction, it can be inferred that the tetragonal and monoclinic phases were present in the support. Nevertheless, an increasing trend of the $\mathrm{m}-\mathrm{Zr}$ strong signal at $460 \mathrm{~cm}^{-1}$ was observed at the expense of the $\mathrm{t}-\mathrm{Zr}$ phase after reaction. This same trend can be observed in the spectra of the Co-containing materials. In the latter sample, a more acute and defined signal of $\mathrm{Co}_{3} \mathrm{O}_{4}$ can be additionally seen, from which the increase of the said particles under reducing atmosphere can be inferred. However, for the $\mathrm{Cu}_{16} \mathrm{Fe}_{7} / \mathrm{Zr}$ material, after being under reducing reaction conditions, $\mathrm{t}-\mathrm{Zr}$ was still the main phase. Moreover, no signals of $\mathrm{Cu}$ or Fe oxides were observed, which highlights the high stability of these species in the said reaction atmosphere, which is also consistent with what was observed for this catalyst after $\mathrm{CO}$ oxidation in oxidizing atmosphere (Figure 6). 


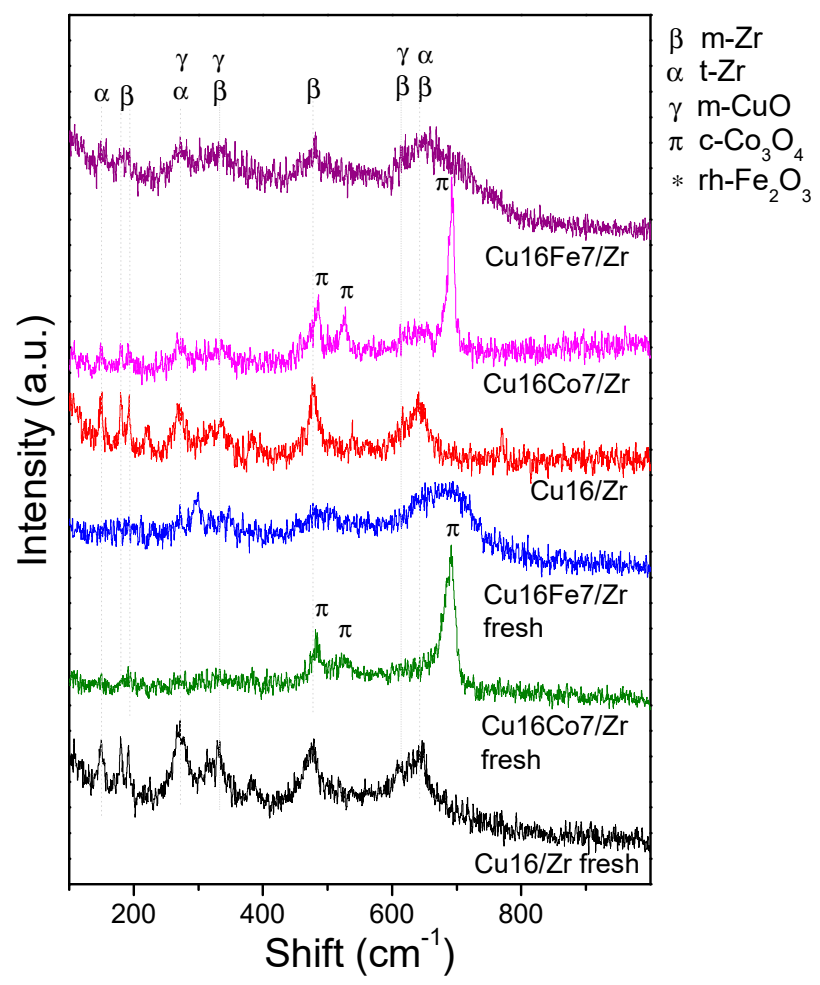

Figure 10. LRS spectra of the bimetallic nanocatalysts before and after the COProx reaction.

\section{Conclusions}

UiO-66 crystals obtained through a sustainable protocol were used as a dispersion matrix for copper, cobalt, and iron species, allowing the preparation of new nanostructured catalysts active in the oxidation of carbon monoxide. The MOF was modified with the said non-noble metals through simple and classic methods of incipient wetness impregnation, followed by controlled thermal treatments. It was shown that, by precisely tuning the treatment atmosphere $(\mathrm{He})$, temperature $\left(225^{\circ} \mathrm{C}\right)$, and time (2h), the solid $\mathrm{Cu} / \mathrm{UiO}-66$ could be obtained having $10 \mathrm{wt} . \%$ copper species in a very high dispersion inside UiO-66 crystals, maintaining the structure of the MOF. This solid proved to be an active catalyst for the $\mathrm{CO}$ oxidation in air streams, representing a novel nanocatalyst not only for this reaction but also for others that demand a high dispersion of active copper species. It was also shown that, if the thermal decomposition treatments of the impregnated metal precursors were carried out in air at temperatures higher than $400{ }^{\circ} \mathrm{C}$, the capacity of the MOF to host metallic species could be used to obtain non-noble metal-based catalysts supported on nano-zirconia derived from UiO-66. These controlled treatments in an air atmosphere of $\mathrm{Cu}, \mathrm{Co}$, or Fe-impregnated UiO-66 promoted the rapid development of a solid composed of tetragonal $(\mathrm{t}-\mathrm{Zr})$ and monoclinic $(\mathrm{m}-\mathrm{Zr})$ zirconia, supporting highly dispersed transition metal oxides. The derived bimetallic $\mathrm{Cu}-\mathrm{Fe} / \mathrm{ZrO}_{2}$ nanocatalyst exhibited the best levels of activity and stability both in the oxidation of $\mathrm{CO}$ in air and in the COProx reaction, due to synergic effects of the very close contact between such oxides in the homogeneous nanomaterial.

This study shows the potential of UiO-66 as a dispersion matrix for low-cost and abundant metals such as copper, cobalt, and iron to obtain new sustainable nanocatalysts active in the $\mathrm{CO}$ oxidation reaction.

Supplementary Materials: The following are available online at http://www.mdpi.com/2079-4991/10/1/165/s1: S1: Incipient wet impregnation procedure; Figure S1: Diffractogram of the synthesized UiO-66 crystals and the pattern simulated from its crystallographic archive (CCDC 733458). The diffractogram of the benzenedicarboxylic acid ligand (BDC) is also included; Figure S2: SDTA of $\mathrm{UiO}-66(\mathrm{M}), \mathrm{Cu} / \mathrm{M}$, and copper precursor: (a) under $\mathrm{N}_{2}$ atmosphere; (b) under air atmosphere; Figure S3: Thermal stability of $\mathrm{Co} / \mathrm{M}, \mathrm{Fe} / \mathrm{M}$ solids, and their respective precursors in air: (a) TGA; (b) dTGA; (c) SDTA. Figure S4: Co/Zr and Fe/Zr nanocatalysts: (a) catalytic behavior; (b) XRD patterns after reaction. 
Author Contributions: Conceptualization, M.A.U. and J.M.Z.; formal analysis, B.M.C.F., M.A.U., and J.M.Z.; funding acquisition, J.M.Z.; investigation, L.A.L., B.M.C.F., and J.M.Z.; methodology, L.A.L.; project administration, J.M.Z.; supervision, M.A.U. and J.M.Z.; writing-original draft, L.A.L., B.M.C.F., M.A.U., and J.M.Z.; writing - review and editing, M.A.U. and J.M.Z. All authors discussed the results and contributed to the manuscript. All authors read and agreed to the published version of the manuscript.

Funding: This research was funded by the Agencia Nacional de Promoción Científica y Tecnológica (ANPCyT) of Argentina under project PICT 2241 and by the Universidad Nacional del Litoral under project CAI+D 00071 LI.

Acknowledgments: We acknowledge the financial support from the Agencia Nacional de Promoción Científica y Tecnológica of Argentina (PICT 2241) and from the Universidad Nacional del Litoral (CAI+D 0071). The institutional support of CONICET is also acknowledged.

Conflicts of Interest: The authors declare no conflicts of interest.

\section{References}

1. Farrusseng, D.; Aguado, S.; Pinel, C. Metal-organic frameworks: Opportunities for catalysis. Angew. Chem. Int. Ed. 2009, 48, 7502-7513. [CrossRef]

2. Falcaro, P.; Ricco, R.; Yazdi, A.; Imaz, I.; Furukawa, S.; Maspoch, D.; Ameloot, R.; Evans, J.D.; Doonan, C.J. Application of metal and metal oxide nanoparticles@MOFs. Coord. Chem. Rev. 2016, 307, 237-254. [CrossRef]

3. Vermoortele, F.; Ameloot, R.; Alaerts, L.; Matthessen, R.; Carlier, B.; Ramós Fernandez, E.V.; Gascon, J.; Kapteijn, F.; De Vos, D.E. Tuning the catalytic performance of metal-organic frameworks in fine chemistry by active site engineering. J. Mater. Chem. 2012, 22, 10313-10321. [CrossRef]

4. Lescouet, T.; Kockrick, E.; Bergeret, G.; Pera-Titus, M.; Farrusseng, D. Engineering MIL-53(Al) flexibility by controlling amino tags. Dalton Trans. 2011, 40, 11359-11361. [CrossRef]

5. Juan-Alcañiz, J.; Gascon, J.; Kapteijn, F. Metal-organic frameworks as scaffolds for the encapsulation of active species: State of the art and future perspectives. J. Mater. Chem. 2012, 22, 10102-10118. [CrossRef]

6. Song, Y.; Li, X.; Sun, L.; Wang, L. Metal/metal oxide nanostructures derived from metal-organic frameworks. RSC Adv. 2015, 5, 7267-7279. [CrossRef]

7. Sun, J.-K.; Xu, Q. Functional materials derived from open framework templates/precursors: Synthesis and applications. Energy Environ. Sci. 2014, 7, 2071-2100. [CrossRef]

8. Zamaro, J.M.; Pérez, N.C.; Miró, E.E.; Casado, C.; Seoane, B.; Téllez, C.; Coronas, J. HKUST-1 MOF: A matrix to synthesize $\mathrm{CuO}$ and $\mathrm{CuO}-\mathrm{CeO}_{2}$ nanoparticle catalysts for $\mathrm{CO}$ oxidation. Chem. Eng. J. 2012, 195-196, 180-187. [CrossRef]

9. Green, E.; Short, S.; Shuker, L.K.; Harrison, P.T.C. Carbon Monoxide Exposure in the Home Environment and the Evaluation of Risks to Health-A UK Perspective. Indoor Built Environ. 1999, 8, 168-175. [CrossRef]

10. Xanthopoulou, G.G.; Novikov, V.A.; Knysh, Y.A.; Amosov, A.P. Nanocatalysts for Low-Temperature Oxidation of CO: Review. Eurasian Chem. J. 2015, 17, 17-32. [CrossRef]

11. Mishra, A.; Prasad, R. A Review on Preferential Oxidation of Carbon Monoxide in Hydrogen Rich Gases. Bull. Chem. React. Eng. Catal. 2011, 6, 1-14. [CrossRef]

12. Bion, N.; Epron, F.; Moreno, M.; Mariño, F.; Duprez, D. Preferential oxidation of carbon monoxide in the presence of hydrogen (PROX) over noble metal and transition metal oxides: Advantages and drawbacks. Top. Catal. 2008, 51, 76-88. [CrossRef]

13. Royer, S.; Duprez, D. Catalytic Oxidation of Carbon Monoxide over Transition Metal Oxides. ChemCatChem 2011, 3, 24-65. [CrossRef]

14. Firsova, A.A.; Khomenko, T.I.; Sil'chenkova, O.N.; Korchak, V.N. Oxidation of Carbon Monoxide in the Presence of Hydrogen on the $\mathrm{CuO}, \mathrm{CoO}$, and $\mathrm{Fe}_{2} \mathrm{O}_{3}$ oxides supported on $\mathrm{ZrO}_{2}$. Kinet. Catal. 2010, 51, 299-311. [CrossRef]

15. Zhao, Z.; Yung, M.M.; Ozkan, U.S. Effect of support on the preferential oxidation of CO over cobalt catalysts. Catal. Commun. 2008, 9, 1465-1471. [CrossRef]

16. Liang, Q.; Zhao, Z.; Liu, J.; Wei, Y.C.; Jiang, G.Y.; Duan, A.J. Pd nanoparticles deposited on metal-organic framework of MIL-53(AI): An active catalyst for CO oxidation. Acta Phys.-Chim. Sin. 2014, 30, 129-134.

17. Jiang, H.; Liu, B.; Akita, T.; Haruta, M.; Sakurai, H.; Xu, Q. Au@ ZIF-8: CO oxidation over gold nanoparticles deposited to metal-organic framework. J. Am. Chem. Soc. 2009, 131, 11302-11303. [CrossRef] [PubMed]

18. Morris Bullock, R. Reaction: Earth-Abundant Metal Catalysts for Energy Conversions. Chem 2017, 2, 444-446. [CrossRef] 
19. Ludwig, J.R.; Schindler, C.S. Catalyst: Sustainable Catalysis. Chem 2017, 2, 313-316. [CrossRef]

20. Cavka, J.H.; Jakobsen, S.; Olsbye, U.; Guillou, N.; Lamberti, C.; Bordiga, S.; Lillerud, K.P. A new Zirconium inorganic building brick forming metal organic frameworks with exceptional stability. J. Am. Chem. Soc. 2008, 130, 13850-13851. [CrossRef]

21. Abdel-Mageed, A.M.; Rungtaweevoranit, B.; Parlinska-Wojtan, M.; Xiaokun, P.; Yaghi, O.M.; Behm, R.J. Highly Active and Stable Single-Atom Cu Catalysts Supported by a Metal-Organic Framework. J. Am. Chem. Soc. 2019, 141, 5201-5210. [CrossRef]

22. Wang, H.L.; Yeh, H.; Chen, Y.C.; Lai, Y.C.; Lin, C.Y.; Lu, K.Y.; Ho, R.M.; Li, B.H.; Lin, C.H.; Tsai, D.H. Thermal Stability of Metal-Organic Frameworks and Encapsulation of $\mathrm{CuO}$ Nanocrystals for Highly Active Catalysis. ACS Appl. Mater. Interfaces 2018, 10, 9332-9341. [CrossRef] [PubMed]

23. Zhu, C.; Ding, T.; Gao, W.; Ma, K.; Tian, Y.; Li, X. CuO/CeO 2 catalysts synthesized from Ce-UiO-66 metal-organic framework for preferential CO oxidation. Int. J. Hydrog. Energy 2017, 42, 17457-17465. [CrossRef]

24. Yu, J.; Yu, J.; Wei, Z.; Guo, X.; Mao, H.; Mao, D. Preparation and Characterization of UiO-66-Supported $\mathrm{Cu}-\mathrm{Ce}$ Bimetal Catalysts for Low-Temperature CO Oxidation. Catal. Lett. 2019, 149, 496-506. [CrossRef]

25. Lozano, L.A.; Iglesias, C.M.; Faroldi, B.M.C.; Ulla, M.A.; Zamaro, J.M. Efficient solvothermal synthesis of highly porous UiO-66 nanocrystals in dimethylformamide-free media. J. Mater. Sci. 2018, 53, 1862-1873. [CrossRef]

26. Wu, H.; Chua, Y.S.; Krungleviciute, V.; Tyagi, M.; Chen, P.; Yildirim, T.; Zhou, W. Unusual and highly tunable missing-linker defects in zirconium metal-organic framework UiO-66 and their important effects on gas adsorption. J. Am. Chem. Soc. 2013, 135, 10525-10532. [CrossRef]

27. Yan, X.; Lu, N.; Fan, B.; Bao, J.; Pan, D.; Wang, M.; Li, R. Synthesis of mesoporous and tetragonal zirconia with inherited morphology from metal-organic frameworks. CrystEngComm 2015, 17, 6426-6433. [CrossRef]

28. Gawande, M.B.; Goswami, A.; Felpin, F.X.; Asefa, T.; Huang, X.; Silva, R.; Zou, X.; Zboril, R.; Varma, R.S. Cu and Cu-Based Nanoparticles: Synthesis and Applications in Catalysis. Chem. Rev. 2016, 116, 3722-3811. [CrossRef]

29. Müller, M.; Hermes, S.; Kähler, K.; Van den Berg, M.W.E.; Muhler, M.; Fischer, R.A. Loading of MOF-5 with $\mathrm{Cu}$ and $\mathrm{ZnO}$ Nanoparticles by Gas-Phase Infiltration with Organometallic Precursors: Properties of Cu/ZnO@MOF-5 as Catalyst for Methanol Synthesis. Chem. Mater. 2008, 20, 4576-4587. [CrossRef]

30. Yang, Z.; Mao, D.; Guo, X.; Lu, G. CO oxidation over $\mathrm{CuO}$ catalysts supported on $\mathrm{CeO}_{2}-\mathrm{ZrO}_{2}$ prepared by microwave assisted co-precipitation: The influence of $\mathrm{CuO}$ content. J. Rare Earths 2014, 32, 117-123. [CrossRef]

31. Morales, F.; Viniegra, M.; Arroyo, R.; Córdoba, G.; Zepeda, T.A. CO oxidation over CuO/ZrO 2 catalysts: Effect of loading and incorporation procedure of CuO. Mater. Res. Innnov. 2010, 14, 183-188. [CrossRef]

32. Ribeiro, N.F.P.; Souza, M.V.M.; Schmal, M. Combustion synthesis of copper catalysts for selective CO oxidation. J. Power Sources 2008, 179, 329-334. [CrossRef]

33. Pokrovski, K.; Jung, K.T.; Bell, A.T. Investigation of $\mathrm{CO}$ and $\mathrm{CO}_{2}$ Adsorption on Tetragonal and Monoclinic Zirconia. Langmuir 2001, 17, 4297-4303. [CrossRef]

34. Soliman, N.K. Factors affecting CO oxidation reaction over nanosized materials: A review. J. Mater. Res. Technol. 2019, 8, 2395-2407. [CrossRef]

35. Li, D.; Liu, X.; Zhang, Q.; Wang, Y.; Wan, H. Cobalt and Copper Composite Oxides as Efficient Catalysts for Preferential Oxidation of $\mathrm{CO}$ in $\mathrm{H}_{2}$-Rich Stream. Catal. Lett. 2009, 127, 377-385. [CrossRef]

36. Yeste, M.P.; Vidal, H.; García-Cabeza, A.L.; Hernández-Garrido, J.C.; Guerra, F.M.; Cifredo, G.A.; González-Leal, J.M.; Gatica, J.M. Low temperature prepared copper-iron mixed oxides for the selective CO oxidation in the presence of hydrogen. Appl. Catal. A Gen. 2018, 552, 58-69. [CrossRef]

37. Said, A.E.A.A.; Abd El-Wahab, M.M.M.; Goda, M.N. Synthesis and characterization of pure and (Ce, Zr, $\mathrm{Ag}$ ) doped mesoporous $\mathrm{CuO}-\mathrm{Fe}_{2} \mathrm{O}_{3}$ as highly efficient and stable nanocatalystsfor $\mathrm{CO}$ oxidation at low temperature. Appl. Surf. Sci. 2016, 390, 649-665. [CrossRef]

38. Cabello, A.P.; Ulla, M.A.; Zamaro, J.M. CeO/CuOx nanostructured films for $\mathrm{CO}$ oxidation and $\mathrm{CO}$ oxidation in hydrogen-rich streams using a micro-structured reactor. Top. Catal. 2019, 62, 931-940. [CrossRef]

39. Yung, M.M.; Zhao, Z.; Woods, M.P.; Ozkan, U.S. Preferential oxidation of carbon monoxide on $\mathrm{CoOx}_{2} / \mathrm{ZrO}_{2}$. J. Mol. Catal. A Chem. 2008, 279, 1-9. [CrossRef]

(C) 2020 by the authors. Licensee MDPI, Basel, Switzerland. This article is an open access article distributed under the terms and conditions of the Creative Commons Attribution (CC BY) license (http://creativecommons.org/licenses/by/4.0/). 